\title{
Competencias y legitimación ante el Tribunal Administrativo Central de Recursos Contractuales (TACRECO): especial consideración de los supuestos de nulidad contractual
}

\author{
Manuel Pulido Quecedo \\ Doctor en Derecho \\ Letrado del Parlamento de Navarra. Antiguo Letrado del Tribunal Constitucional \\ mpulidoq@parlamentodenavarra.es
}

\begin{abstract}
Resumen
En el presente articulo partiendo de la preocupación comunitaria por desterrar las adjudicaciones ilegales, se estudia la naturaleza del Tribunal Administrativo Central de Recursos Contractuales (TACRECO) como órgano común al servicio de la Administración General del Estado y de otros órganos tal como expresa hoy el articulo 41.1 del Texto Refundido de la ley de Contratos del Sector Público aprobado por el Real Decreto legislativo 3/2011, de 14 de noviembre (en adelante, TRLCSP), sin perjuicio de que su carácter de órgano especializado que actúa con plena independencia funcional en el ejercicio de sus competencias, le permita conocer también de los recursos especiales que se susciten contra los actos de los órganos competentes del Consejo General del Poder Judicial, del Tribunal Constitucional y del Tribunal de Cuentas. En concreto el autor estudia el recurso especial en materia de contratación como objeto de resolución por el tribunal administrativo central de recursos contractuales y en especial los aspectos que tienen con su legitimación y competencia. prestando especial atención a los supuestos de nulidad contractual. Concluye con la propuesta de que el TACRECO en su labor de decir el derecho en esta materia se configure a modo del TEAC en el ámbito de a AGE irradiando y proyectando sus resoluciones a los demás órganos que se creen.
\end{abstract}

Palabras clave Tacreco, Contratos del sector publico, jurisdicción contencioso administrativa, Nulidad contractual, procedimienteo cuestión de nulidad contractual, Recurso especial.

\section{Appearance and legitimation in the Public Procurement Review Central Administrative Court: with particular regard to nullity of contract cases}

\begin{abstract}
Based on the EC's determination to stamp out illegal awards, this article analyses the nature of the Public Procurement Review Central Administrative Court (whose Spanish acronym is TACRECO), a common body at the service of the Central State Administration and other bodies, as is currently established in article 41.1 of the Consolidated Text of the Law on Public-sector Contracts, approved under Royal Legislative Decree 3/2011, of 14 November (hereinafter referred to as (TLPSC). Its nature of a specialised body which acts with full functional independence in the exercise of its powers also enables it to assess the special reviews arising against the decisions of the competent bodies of the General Council of the Judiciary, the Constitutional Court and Court of Auditors. Specifically, the author analyses the special review concerning public procurement as subject of resolution by the Public Procurement Review Central Administrative Court, and in particular the aspects which have to do with its legitimation and competence, paying special attention to nullity of contract cases. The article concludes with the suggestion that the TACRECO, in its duty to resolve these reviews, establishes itself like the Central Economic Administrative Court (CEAC) in the sphere of the Central State Administration, irradiating and projecting its decisions onto the other bodies to be established.

Key words

TACRECO, Public-sector contracts, Contentious-administrative jurisdiction, Nullity of contract, Nullity of contract procedure, Special review.
\end{abstract}




\section{EL TRIBUNAL ADMINISTRATIVO CENTRAL DE RECURSOS CONTRACTUALES: BREVE REFERENCIA A SU NATURALEZA Y FUNCIONES EN MATERIA DE CONTRATACIÓN PÚBLICA}

Han transcurrido ya más de un año ${ }^{1}$ desde que el Tribunal Administrativo Central de Recursos Contractuales entró en funcionamiento, una vez nombrados sus miembros de manera rápida y eficaz ${ }^{2}$.

Con su creación se venía a dar solución -como señalamos en nuestro libro El nuevo Tribunal Administrativo Central de Recursos Contractuales'- a las cuitas del Reino de España con las instituciones comunitarias en esta materia.

Podría en tal sentido señalarse que la modificación de la legislación de Contratos públicos, en especial de las leyes 30 y 31/2007, es hija de la preocupación comunitaria por desterrar las adjudicaciones ilegales. Si la lucha contra las inmunidades del poder que teorizó el Prof. García de Enterría hace ya cincuenta años dejó de ser ya hace tiempo una cuestión preocupante -salvo, en nuestro tiempo, por algunos excesos judiciales-, no puede decirse lo mismo del control de las adjudicaciones ilegales que encuentra ahora su réplica en el ámbito de la legislación de contratos, en la lucha contra la adjudicación directa ilegal, causantes de tantos favores y dispendios, a los que la Directiva 2007/66/CE, de 11 de diciembre, trata de poner cerco sobre la base de la divisa de transparencia y no discriminación en la contratación pública.

La respuesta que ha dado el Legislador nacional a esta cuestión con la creación del Tribunal Administrativo Central de Recursos Contractuales enlaza con la preocupación del legislador comunitario de poner en manos de un órgano diverso del poder adjudicador, el control efectivo de las adjudicaciones ilegales, otorgándole poderes inusuales, que obligan a considerarlo como un órgano con cuerpo administrativo, pero alma cuasi judicial, del que se espera que actúe con imparcialidad e independencia y que sea un revulsivo para atajar las malas practicas de que adolece nuestra adjudicación en materia de contratación pública.

Nació el TACRECO con vocación de ser un órgano común al servicio de la Administración General del Estado y de otros órganos tal como expresa hoy el articulo 41.1 del Texto Refundido de la ley de Contratos del Sector Público aprobado por el Real Decreto legislativo 3/2011, de 14 de noviembre (en adelante, TRLCSP) ${ }^{4}$, sin perjuicio de que su carácter de órgano especializado que actúa con plena independencia funcional en el

1 Este artículo terminó de redactarse en Pamplona, el día 18 de noviembre de 2011

2 Por Resoluciones de la Subsecretaria de Hacienda de 15 de octubre se dió publicidad a los acuerdos del Consejo de Ministros de 15 de octubre de 2010, por los que se nombra a D. Juan José Pardo Garcia Valdecasas, Presidente y a D ${ }^{a}$ Carmen Gomis Bernal y Don José Santos Santamaría Cruz respectivamente, vocales del mencionado Tribunal (en adelante se citará abreviadamente TACRECO).

3 Véase Pulido Quecedo, M. El nuevo Tribunal Administrativo Central de Recursos Contractuales, Aranzadi, Pamplona, 2010. Lógicamente lo aquí expuesto es en parte tributario de lo allí tratado.

664 Publicado en el BOE núm. 276, de 16 de noviembre de 2011. 
ejercicio de sus competencias, le permita conocer también de los recursos especiales que se susciten contra los actos de los órganos competentes del Consejo General del Poder Judicial, del Tribunal Constitucional y del Tribunal de Cuentas 5 . No así de las Cortes Generales que han hecho valer su autonomía ex art 72 CE para regular su propio Tribunal de Recursos Contractuales ${ }^{6}$ y por consecuencia, las Asambleas Legislativas de las Comunidades Autónomas, alguna de los cuales han aprobado ya como Cataluña ${ }^{7}$ y Murcia ${ }^{8}$ y otros están en trámite de regulación, sus propios Tribunales administrativos contractuales para preservar su autonomía normativa y organizativa.

No gastaremos, por ello, en los estrictos limites de espacio fijados por el Coordinador de este número de la Revista, don Martín Bassols, tiempo alguno en destacar al modo habitual en trabajos de esta naturaleza, el alcance subjetivo del TACRECO pues está claramente definido ${ }^{9}$, como se señaló en el debate de la ley en las Cortes Generales por la diputada ponente Sra. Batet en el verano del $2010^{10}$, estando abierto

5 Cuestión distinta plantea la redacción del apartado 4 del art. 311 de la Ley 34/2010 relativa a los poderes adjudicadores que no tengan la consideración de administraciones públicas. Véase, en tal sentido Pulido Quecedo, M. El nuevo Tribunal Administrativo Central de Recurso Contractuales, op. cit, pág, 61 y ss.

6 Véase, la Resolución de 18 de enero de 2011, del Letrado Mayor de las Cortes Generales, por la que se publica la de 21 de diciembre de 2010, de las Mesas del Congreso de los Diputados y del Senado, por la que se crea el Tribunal de Recursos Contractuales de las Cortes Generales (BOE núm. 21, de 25 de enero de 2011).

7 Acuerdo de 1 de marzo de 2011 por el que se crea el Tribunal de Recursos Contractuales del Parlamento de Cataluña

8 Véase el Acuerdo de 14 de abril de 2011 de la Asamblea de Murcia por la que se aprueba la Normativa en materia de contratación de la Asamblea Regional de Murcia, donde se crea el Tribunal de Recursos Contractuales, como el órgano que deba conocer, en el ámbito de contratación de la Asamblea Regional de Murcia y el defensor del pueblo, del recurso especial de contratación regulado en el libro VI de la ley 30/2007, de contratos del sector público.(BARM NÚMERO 144 / 29 DE ABRIL DE 2011)

9 El art. 311 contempló, en su párrafo 2 (Ley 34/2010) contempló, la posibilidad de que las Comunidades Autónomas creen un órgano similar al Tribunal Administrativo Central de recursos contractuales.

En tal sentido dispone que en el ámbito de las Comunidades Autónomas, así como en el de los órganos competentes de sus Asambleas Legislativas y de las instituciones autonómicas análogas al Tribunal de Cuentas y al Defensor del Pueblo la competencia para resolver los recursos será establecida por sus normas respectivas, debiendo crear un órgano independiente cuyo titular, o en el caso de que fuera colegiado al menos su Presidente, ostente cualificaciones jurídicas y profesionales que garanticen un adecuado conocimiento de las materias de que deba conocer.

En cuanto a las Corporaciones locales, el apartado 3 del art. 311 de la Ley 30/2007 en la redacción que le da la Ley 34/2010, estableció lo siguiente:

3. En el ámbito de las Corporaciones Locales, la competencia para resolver los recursos será establecida por las normas de las Comunidades Autónomas cuando éstas tengan atribuida competencia normativa y de ejecución en materia de régimen local y contratación.

En el supuesto de que no exista previsión expresa en la legislación autonómica, la competencia corresponderá al mismo órgano al que las Comunidades Autónomas en cuyo territorio se integran las Corporaciones Locales hayan atribuido la competencia para resolver los recursos de su ámbito.

10 "Respecto al contenido, queremos destacar que en este proyecto de ley hay un escrupuloso respeto de la distribución competencial existente y marcada por la Constitución y los Estatutos de Autonomía, es decir, el bloque de constitucionalidad. Las Comunidades autónomas pueden crear un tribunal específico, con la condición de que en todo caso este sea también independiente, que es el mandato que viene dado por Europa. Nos parece más adecuado no establecer condicionantes respecto a este órgano autonómico, como proponían por ejemplo las enmiendas 2 y 3 de UPyD, o la 8 del Grupo Popular, ya que incluso puede que por el volumen de contrataciones, y en consecuencia la previsión de recursos, sea tan reducido el número de recursos interpuestos que las comunidades autónomas decidan no constituir un órgano 
a futuras colaboraciones vía Convenio con otros órganos de las CC.AA y de las Corporaciones locales. Aspecto este que me parece importante destacar en los tiempos que vivimos donde no todo lo superfluo en materia de organización administrativa existente en nuestro Estado recae necesariamente bajo la responsabilidad de las Comunidades Autónomas.

EI TACRECO por el número de supuestos que ha conocido y por el número de resoluciones que ha puesto -más de doscientas en el tiempo que lleva funcionandoestá llamado a descentralizarse, tal como recuerda de nuevo la disposición adicional trigésima del novísimo TRLCSP.

EI TACRECO con su labor casuística al modo pretoriano de la Jurisprudencia emanada del Tribunal de Justicia de las Comunidades Europea está llamado a convertirse en un órgano de referencia en materia de contratación pública, como lo demuestra ya el numero de resoluciones puestas. No hemos podido, sin embargo, examinar en este trabajo el alcance y significado de esta primera aproximación del TACRECO en su labor resolutiva ni tampoco por prematura, reparar en la labor de los Tribunales de Justicia en la convalidación o no de sus criterios, sobre las nuevas competencias que la legislación le encomienda.

Es importante que el TACRECO se configure a modo del TEAC en el ámbito de la AGE irradiando y proyectando sus resoluciones a los demás órganos que se creen, puesto que si el acierto no le acompaña en su función de control cuasijudicial o se inclina por la contemporización con lo vigente con arreglo a nuestras inercias y malas practicas administrativas, solo quedará la respuesta judicial sin intermediación administrativa, lo que exigirá una reforma de mayor alcance y significado de nuestra Jurisdicción Contencioso-Administrativa o la creación de Tribunal Judiciales "Ad hoc" en materia de Contratación.

\section{COMPETENCIAS Y LEGITIMACIÓN}

\section{II.1. El recurso especial en materia de contratación como objeto de resolución por el Tribunal Administrativo Central de recursos contractuales}

\section{A) Antecedentes de la regulación del recurso especial en materia de contratación}

La razón de ser de la Ley 34/2010 11 -como recordó el Consejo de Estado al Dictaminar el Anteproyecto de Ley- se encuentra en la necesidad de adaptar la legislación

análogo ni colegiado ni en forma de tribunal, sino que sea por ejemplo un órgano unipersonal (Intervención de la diputada socialista Sra. Batet Lamaña en DSCD. Comisión de Economía y Hacienda, núm. 576, de 22 de junio de 2010, pág. 25).

11 Hoy recogida en el Texto Refundido de la ley de Contratos del Sector Público aprobado por Real 68 Decreto Legislativo 3/2011, de 14 de noviembre (BOE núm. 276, de 16 de noviembre) 
interna de contratación, esto es, las leyes 30 y 31/2007, a la Directiva 2007/66CE del Parlamento Europeo y del Consejo, de 11 de diciembre, por lo que se refiere a la mejora de la eficacia de los procedimientos de recursos en materia de adjudicación de contratos públicos.

En particular, la Directiva que se traspone trata de articular un sistema de recursos rápidos y eficaces, cuya resolución se encomienda al Tribunal Administrativo Central de Recursos Contractuales, para agilizar y reforzar las garantías de transparencia y no discriminación prevista en las llamadas Directivas de contratos ${ }^{12}$.

A lo que cabe agregar, el procedimiento de infracción abierto al Reino de España por la Comisión Europea sobre incumplimiento de las obligaciones que le incumben en virtud del articulo 2 apartado 1, letras a) y b) del Directiva 89/665/CEE, de 21 de diciembre de 1989, al no prever un plazo obligatorio para que la entidad adjudicadora notifique la decisión de adjudicación de un contrato a todos los licitadores y al no prever un plazo de espera obligatorio entre la adjudicación del contrato y su adjudicación.

Como se recoge, de manera pormenorizada en el Dictamen del Consejo de Estado, la Comisión Europea considera:

“ A través de la Carta de emplazamiento 228 2190/2002 la Comisión Europea señala que la nueva Ley 30/2007 no cumple las exigencias derivadas del aludido faIlo del Tribunal de Justicia [STJUE, de abril de 2008] e invita al Gobierno español a remitirle sus observaciones en un plazo de dos meses. En informe de la Secretaría General Técnica del Ministerio de Economía y Hacienda de fecha 25 de febrero de 2009, se da respuesta a las observaciones formuladas por la Comisión y se concluye que la Ley 30/2007 cumple las exigencias derivadas de la sentencia".

\section{B) La nueva regulación proyectada según la doctrina del Consejo de Estado:}

\section{a) La supresión de la distinción entre adjudicación provisional y definitiva}

El Consejo de Estado en su Dictamen de 29 de abril de 2010, informó sobre la nueva regulación proyectada en el Anteproyecto que coincide con la redacción definitiva de la nueva regulación que introduce en la Ley 30/2007, la Ley 34/2010 al adicionar un LIBRO VI, intitulado: "Régimen especial de revisión de decisiones en materia de contratación y medios alternativos de resolución de conflictos”.

12 Directiva 89/655/CEE del Consejo de 21 de diciembre de 1989, relativa a la coordinación de las disposiciones legales, reglamentarias y administrativas referentes a la aplicación de los procedimientos de recursos en materia de adjudicación de los contratos públicos de suministros y de obras (conocida como Directiva de recursos),y la Directiva 92/13/CEE del Consejo, de 25 de febrero de 1992, relativa a la coordinación de las disposiciones legislativas, reglamentarias y administrativas referentes a la aplicación de las normas comunitarias en los procedimientos de formalización de contratos de las entidades que operen en los sectores del agua, de la energía, de los transportes y de las telecomunicaciones. 
Para dar cumplimiento a las anteriores exigencias, se instrumentan en el anteproyecto de Ley sometido a consulta las siguientes medidas:

- Por un lado, se suprime la dualidad entre adjudicación provisional y adjudicación definitiva. De modo resumido, la razón de ser de esta supresión es que, a juicio de la Comisión, el recurso contra la adjudicación provisional no equivale al recurso contra la adjudicación misma del contrato y no permite a los licitadores excluidos enjuiciar la corrección de todas las actuaciones posteriores a dicha adjudicación provisional, considerando por ello que se trata de un recurso ineficaz. En esta línea, se da nueva redacción al artículo 135 de la Ley 30/2007. (y se introducen los ajustes oportunos en otros preceptos de la citada Ley).

- Por otro lado, se hace necesario articular algún mecanismo por virtud del cual el contrato no se entienda perfeccionado hasta que transcurra el plazo para interponer recurso o hasta que se resuelva sobre el recurso mismo o sobre el mantenimiento de la suspensión. De ahí que se modifique la regla por virtud de la cual los contratos se perfeccionan mediante su adjudicación, estableciéndose que su perfeccionamiento se verifica con su formalización (artículo 27 de la Ley 30/2007).

"Ha de hacerse notar, por lo demás, que, por lo que se refiere a este punto concreto, las medidas legislativas proyectadas afectan fundamentalmente a la Ley 30/2007 (aunque en la Ley 31/2007 también se contiene alguna previsión al respecto)”.

b) La trasformación de la naturaleza de los contratos del sector publico.

La formalización como presupuesto constitutivo del mismo.

La primera reflexión que debe realizarse se refiere a la transformación que se produce en la naturaleza de los contratos del sector público.

Tradicionalmente y con arreglo al marco normativo vigente, es claro que la contratación administrativa es eminentemente formalista. De hecho, la Administración no puede contratar verbalmente (artículo 28 de la Ley) y el inicio de la ejecución del contrato depende, como regla general, de su formalización. Ahora bien, la forma escrita, aunque obligatoria, carece hasta la fecha de carácter constitutivo. El contrato se perfecciona con la adjudicación (definitiva, según la Ley 30/2007), no con la formalización, y desde ese mismo momento existe y obliga como tal. El incumplimiento de la obligación de formalizar el contrato no afecta a la existencia ni a la validez del contrato; y de ahí que la falta de formalización del contrato por causas imputables al contratista determine su resolución con incautación de la garantía. Se sigue, pues, la regla general de que los contratos se perfeccionan por el solo consentimiento (artículos 1.254 y 1.258 del Código Civil).

Precisamente para preservar el principio antiformalista que hasta ahora ha inspi70 rado la legislación interna en la materia se introdujo en 2007 la dualidad adjudicación 
provisional/adjudicación definitiva. Como se ponía de manifiesto en la memoria que acompañaba el anteproyecto de la que luego sería Ley 30/2007, la recepción del requerimiento recogido en la Directiva 89/665/CEE e inspirado en la Sentencia del Tribunal de Justicia de las Comunidades Europeas de 28 de octubre de 1999, Alcatel Austria AG y otros, Siemens AG Österreich y Sag-Schrack Anlagentechnik AG contra Bundesministerium für Wissenschaft und Verkehr, asunto C-81/98, con arreglo al cual habría de verificarse la inserción de "un periodo de paralización del procedimiento entre la adjudicación del contrato y su formalización (dando por descontado que la perfección del vínculo se produce por medio de ésta) de duración suficiente para permitir la interposición del correspondiente recurso, y la atribución a la presentación de éste de un efecto suspensivo automático", iba a diferir ligeramente del planteamiento expuesto:

\begin{abstract}
"Al objeto de mantener el principio antiformalista que inspira nuestra legislación, se ha desdoblado la decisión de adjudicación en dos trámites, la adjudicación provisional (que se articula, además, a otros efectos...) y la adjudicación definitiva, separados por un lapso de quince días hábiles que jugará el papel del período de congelación procedimental previsto en los trabajos preparatorios de la revisión de la Directiva de recursos. Durante los diez primeros días de ese plazo podrán los interesados interponer el recurso especial en materia de contratación, que producirá de forma automática la suspensión del procedimiento, suspensión que se mantendrá hasta la resolución del recurso".
\end{abstract}

Como se acaba de señalar, la Comisión Europea ha concluido que este esquema no da adecuada respuesta a las exigencias derivadas de la Directiva de recursos y, por ello, además de suprimir la dualidad adjudicación provisional/adjudicación definitiva, la regulación proyectada exige una determinada forma para que los contratos celebrados por los poderes adjudicadores se perfeccionen: la formalización pasa a ser, por tanto, constitutiva del contrato. A partir de esta regla y cuando se trate de supuestos en que procede interponer el recurso especial, se establece que la formalización no podrá efectuarse antes de que transcurran quince días hábiles desde que se remita la notificación de la adjudicación a los licitadores y candidatos; y sólo una vez transcurrido dicho plazo (o cuando se acuerde el levantamiento de la suspensión) el órgano de contratación requerirá al adjudicatario para que formalice el contrato en plazo no superior a cinco días a contar desde el siguiente a aquel en que hubiera recibido el requerimiento (redacción proyectada para el artículo 140.3).

Se altera, pues, el carácter antiformalista de la contratación pública en relación con los contratos celebrados por poderes adjudicadores para dar cumplimiento a las exigencias de la Comisión Europea en cuanto a la adecuación de la legislación interna sobre contratos del sector público a las directivas comunitarias aplicables.

La trascendencia práctica de esta modificación afecta a distintos planos. Quizá el más evidente sea el de la desaparición, como causa de resolución de los contratos, de su falta de formalización; aunque también se deriva alguna consecuencia relevante por razón de la supresión de la dualidad adjudicación provisional/adjudicación definitiva. 
Así, ha resultado preciso ajustar la terminología empleada en diversos artículos (así, artículos 83, 87.1, 91.4 o 135 de la Ley 30/2007) que en la redacción vigente hacen referencia al adjudicatario provisional. El anteproyecto se refiere entonces al licitador que hubiera presentado la oferta económicamente más ventajosa o al licitador cuya proposición hubiera sido seleccionada para la adjudicación.

De otra parte, también cabe apreciar una distinta delimitación de los supuestos a los que ha de entenderse referido ese doble mecanismo, hasta ahora de adjudicación provisional y adjudicación definitiva, y con la entrada en vigor de la futura ley, de adjudicación y formalización. En efecto, con arreglo a la redacción vigente (artículos 27 y 135), ese "periodo de congelación procedimental" que media entre la adjudicación provisional y la definitiva se da en todos los contratos de las Administraciones Públicas, con independencia de sus características, y en los contratos celebrados por las restantes entidades del sector público cuando estén sujetos a regulación armonizada. La regulación proyectada opta, sin embargo, por utilizar un único criterio -el de la celebración del contrato por un poder adjudicador- a la hora de definir el esquema adjudicación/ formalización. Ello supone una mayor homogeneidad en el régimen jurídico aplicable a los contratos celebrados por los poderes adjudicadores, desapareciendo el distinto tratamiento derivado de que los contratos celebrados por dichos poderes estuvieran sujetos o no a regulación armonizada y de que, en definitiva, pudieran ser objeto o no de recurso especial".

\section{C) La nueva regulación contemplada en los articulos 310 de la ley 30/2007 y 110 de la ley $31 / 2007^{13}$}

a) Los actos objeto de recurso de los Contratos enunciados en el art. 310.1

El nuevo articulo 310. 1 (art 40 del Texto Refundido) establece que serán susceptibles de recurso especial en materia de contratación previo a la interposición del contencioso-administrativo, los actos relacionados en el apartado 2 de este mismo artículo, 2, que son los siguientes:

a) Los anuncios de licitación, los pliegos y los documentos contractuales que establezcan las condiciones que deban regir la contratación.

b) Los actos de trámite adoptados en el procedimiento de adjudicación, siempre que éstos decidan directa o indirectamente sobre la adjudicación, determinen la imposibilidad de continuar el procedimiento o produzcan indefensión o perjuicio irreparable a derechos o intereses legítimos. Se considerarán actos de trámite que determinan la imposibilidad de continuar el procedi-

13 Hoy numerado como artículo 40. (Recurso especial en materia de contratación: Actos recurribles), en el Texto Refundido de la Ley de Contratos del Sector Público (Real Decreto Legislativo 3/2011, de 14 de noviembre) 
miento los actos de la Mesa de Contratación por los que se acuerde la exclusión de licitadores.

c) Los acuerdos de adjudicación adoptados por los poderes adjudicadores, cuando se refieran a los siguientes tipos de contratos que pretendan concertar las Administraciones Públicas y las entidades que ostenten la condición de poderes adjudicadores:

a) Contratos de obras, concesión de obras públicas, de suministro, de servicios, de colaboración entre el Sector Público y el Sector Privado y acuerdos marco, sujetos a regulación armonizada.

b) Contratos de servicios comprendidos en las categorías 17 a 27 del Anexo II de esta Ley cuyo valor estimado sea igual o superior a 193.000 euros y

c) Contratos de gestión de servicios públicos en los que el presupuesto de gastos de primer establecimiento, excluido el importe del Impuesto sobre el Valor Añadido, sea superior a 500.000 euros y el plazo de duración superior a cinco años.

Serán también susceptibles de este recurso los contratos subvencionados a que se refiere el artículo 17.

El apartado 4 del art 310 4, (nuevo articulo 40.4 del Texto Refundido) dispone que no "se dará este recurso en relación con los procedimientos de adjudicación que se sigan por el trámite de emergencia regulado en el artículo 97 (nuevo art.113 del Texto Refundido) de esta Ley".

b) Las reclamaciones objeto de recurso ante el TACRECO en los procedimientos de adjudicación y declaración de nulidad de los contratos de la Ley 31/2007

El Tribunal Administrativo Central de Recurso Contractuales será competente o en su caso los órganos previstos en el art. 311 de la Ley 30/200 $7^{14}$, para conocer en relación con las entidades enumeradas en el apartado 1 del artículo 3 de la Ley $31 / 2007^{15}$, así como a las que estén adscritas o vinculadas a ellas, o a las que hayan

14 Art 40 del nuevo TRCSP (RDL 3/2011, de 14 de noviembre). Téngase en cuenta que la disposición derogatoria del articulo único del texto refundido deroga la Ley 30/2007, de 30 de octubre, de Contratos del Sector Público.

15 Art 3. 1. de la Ley 31/2007:

"Quedarán sujetas a la presente Ley, siempre que realicen alguna de las actividades enumeradas en los artículos 7 a 12, las entidades contratantes que sean organismos de derecho público o empresas públicas y las entidades contratantes que sin ser organismos de derecho público o empresas públicas, tengan derechos especiales o exclusivos según se establece en el artículo 4.

Asimismo quedarán sujetas a la presente Ley las asociaciones formadas por varias entidades contratantes las entidades contratantes que sean organismos de derecho público o empresas públicas y las enti- 
otorgado un derecho especial o exclusivo, respecto de los contratos cuyos procedimientos de adjudicación se regulan:

a) Resolver las reclamaciones y cuestiones de nulidad que se planteen por infracción de las normas contenidas en esta Ley.

\section{c) Otras competencias}

1. La resolución de contratos celebrados en el ámbito de la Seguridad pública, en especial los recursos especiales en materia de contratación regulados en el art. 59 de la Ley 24/2011, de 1 de agosto, de Contratos del Sector públicos en los ambitos de defensa y de seguridad y las cuestiones de nulidad, establecidas ene I art. 56 de dicha Ley.

2. Cualquiera otras competencias que le atribuya la ley. En este apartado enunciado a modo de cajón de sastre, cabe señalar que alguna normativa autonómica atribuye a los órganos autonómicos competencias que le atribuya la Unión europea o la normativa estatal básica ${ }^{16}$.

\section{D) La problemática del ámbito objetivo del recurso: la no extensión del recurso especial a todos los contratos}

a) La posición del Consejo de Estado favorable a la universalización del recurso especial a todos los contratos comprendidos en el ámbito de aplicación de la ley $30 / 2007$

Una de las observaciones que más se ha repetido ha sido la relativa a la conveniencia de extender la aplicación de este mecanismo a todos los contratos, y no únicamente a los contratos sujetos a regulación armonizada. Frente a esta opción, se ha dicho que la aplicación extensiva del recurso podría dificultar la eficacia de las previsiones pues se dilataría de forma inconveniente la tramitación de los procedimientos de adjudicación en los contratos de menor entidad económica.

Efectivamente, el apartado 1 del nuevo artículo 310 de la Ley 30/20077 refiere el ámbito de aplicación del recurso a los contratos sujetos a regulación armonizada, por lo que no se extenderá a los restantes contratos del sector público (con las precisiones contenidas en las letras b) y c) del mencionado apartado). A este respecto y como ya

\footnotetext{
dades contratantes que sin ser organismos de derecho público o empresas públicas, tengan derechos especiales o exclusivos según se establece en el artículo 4.

16 Véase en tal sentido el articulo 1.e) del Decreto de la Junta de Andalucía 332/2011, de 2 de noviembre, por el que se crea el Tribunal Administrativo de Recurso Contractuales de la Junta de Andalucía (BOJA, de 11 de noviembre de 2011).

17 Art. 40.1 TRCSP (RDLegislativo 3/2011, de 14 de noviembre
} 
apuntó el Consejo de Estado en el mencionado dictamen 514/2006, “esta distinción entre los mecanismos de control de uno y otro tipo de contratos no está suficientemente justificada y podría generar un cierto nivel de inseguridad jurídica, por lo que debería considerarse su extensión a todos los contratos".

La finalidad que se persigue con el nuevo recurso y el sistema especial de medidas cautelares es, en último término, garantizar que el control del procedimiento de adjudicación sea rápido y eficaz, de modo que las incidencias que puedan plantearse se tramiten y resuelvan antes de celebrarse el contrato. Esa conveniencia de rapidez y eficacia en la resolución de las incidencias del procedimiento de adjudicación resulta extensible a cualquier tipo de contrato, esté o no sujeto a regulación armonizada. Por estas razones, y aun cuando las exigencias de la Directiva de recursos queden cumplidas con aplicar estos mecanismos de garantía a los contratos sujetos a regulación armonizada, sería conveniente valorar su extensión a todos los contratos comprendidos en el ámbito de aplicación de la Ley 30/2007".

b) El recurso al Derecho comparado: el référé précontractuel del contenciosoadministrativo francés: el arrêt Syndicat mixte intercommunal de réalisation et de gestion pour l'élimination des ordures ménagères du secteur Est de la Sarthe, de 3 de octubre de 2008. El ejemplo más restrictivo de Alemania.

El Consejo de Estado ofrece el ejemplo del Derecho administrativo francés, tan caro a nuestros administrativistas:

"Así se ha hecho, por lo demás, en el Derecho francés, cuyo référé précontractuel, aunque creado en cumplimiento de la normativa comunitaria, se extiende al control de la observancia de las reglas de publicidad y concurrencia de todos los contratos, estén o no en el ámbito de aplicación de las directivas. Debe llamarse la atención, sin embargo, sobre el hecho de que el Consejo de Estado francés viene interpretando de modo estricto el artículo L 551-1 del Código de Justicia Administrativa con arreglo al cual se venía considerando que cabía acudir al mecanismo del référé précontractuel incluso cuando no se había producido una lesión derivada de infracción de las normas de publicidad y concurrencia. A partir del arrêt Syndicat mixte intercommunal de réalisation et de gestion pour l'élimination des ordures ménagères du secteur Est de la Sarthe, de 3 de octubre de 2008, se considera que una empresa está legitimada en relación con el aludido recurso únicamente si su pretensión se fundamenta en incumplimientos que, en atención a su alcance y a la fase del procedimiento en que se producen, son susceptibles de haberle causado un perjuicio o implican el riesgo de causárselo, aunque sea de modo indirecto al suponer una ventaja para otra empresa concurrente".

No obstante lo cual, señala:

"Frente al ejemplo francés, otros países, como Alemania, han optado por restringir la aplicación de esta vía especial de recurso a los contratos sujetos a la regulación comunitaria, una solución a la que nada hay que oponer desde el punto de 
vista del cumplimiento de las normas comunitarias, pero que sin duda resulta menos garantista para los administrados".

\title{
E) La naturaleza del recurso especial ex art. $310^{18}$
}

\section{a) Carácter exclusivo y potestativo del recurso}

El recurso especial regulado en el articulo 310 (art 40 TRCSP) se configura, al igual que ocurrió con la anterior del Art. 37 de la Ley 30/2007, como un recurso exclusivo, esto es, incompatible con el esquema ordinario de recursos previstos en la ley 30/1992, salvedad hecha de la tramitación ante el órgano equivalente en el ámbito autonómico tal como prevé el apartado 5 del Art. 310 (hoy art 40.5 del TRCSP), al señalar este último de forma terminante y clara que "que "no procederá la interposición de recursos administrativos ordinarios contra los actos enumerados en este artículo, salvo la excepción prevista en el siguiente con respecto a las Comunidades Autónomas".

No obstante lo cual, salva de la interposición ordinaria aquellos "actos que se dicten en los procedimientos de adjudicación de contratos administrativos que no reúnan los requisitos del apartado 1", al establecer el inciso segundo de dicho apartado 5 que "podrán ser objeto de recurso de conformidad con lo dispuesto en la Ley 30/1992, de 26 de noviembre, de Régimen Jurídico de las Administraciones Públicas y del Procedimiento Administrativo Común, y en la Ley 29/1998 de 13 de julio, reguladora de la Jurisdicción Contencioso Administrativa.

La segunda nota que caracteriza al recurso especial es su alcance potestativo, esto es, innecesario para acudir a la vía jurisdiccional en los términos que más adelante veremos, según señala de forma clara e inequívoca el apartado 6 del art. 310 (Art 40.6 TRCSP), al expresar que "el recurso especial regulado en este artículo y los siguientes tendrá carácter potestativo", siguiendo el consejo del supremo órgano consultivo del gobierno.

En parecidos términos se expresó el Consejo de Estado, al examinar la regulación contemplada en el Anteproyecto, cuya redacción coincide con la finalmente vigente.

\begin{abstract}
"La regulación proyectada mantiene el carácter exclusivo del recurso especial, de modo que no procederá la interposición de recursos administrativos ordinarios contra los actos que se mencionan en el proyectado artículo 310.2 de la Ley 30/2007 (apartado 5 de este mismo artículo). Como ya se dijo en el dictamen 514/2006, es conveniente mantener este carácter exclusivo, sin perjuicio de lo cual se reconoce expresamente la posibilidad de que las Comunidades Autónomas puedan prever la interposición de recurso administrativo previo (segundo párrafo del artículo 311.2 proyectado).
\end{abstract}


Por lo que se refiere al carácter potestativo u obligatorio del recurso, la redacción vigente del artículo 37.1 de la Ley 30/2007 establece que "las decisiones a que se refiere (...) deberán ser objeto del recurso especial en materia de contratación que regula este artículo con anterioridad a la interposición del recurso contencioso-administrativo". Por su parte, el comienzo del apartado 1 del nuevo artículo 310 se expresa en los siguientes términos: "Serán susceptibles de recurso especial en materia de contratación previo a la interposición del contencioso-administrativo los actos...”.

La redacción proyectada apunta hacia la configuración del recurso especial como recurso potestativo. Esta es la solución que el Consejo de Estado considera más acertada, como ya subrayó en 2006. Debe, sin embargo, recogerse en el anteproyecto de forma clara y que no ofrezca lugar a dudas, indicando expresamente que dicho recurso tiene carácter potestativo".

\section{II.2. Los legitimados en el procedimiento}

El Art. 312 de la Ley 30/2007 $7^{19}$, establece que podrá interponer el correspondiente recurso especial en materia de contratación toda persona física o jurídica cuyos derechos o intereses legítimos se hayan visto perjudicados o puedan resultar afectados por las decisiones objeto de recurso.

En principio, por tanto, cualquier licitador estará legitimado para interponer el recurso, cuyos derechos e intereses legítimos hayan podido considerarse afectados.

El articulo 102 de a Ley 31/2007, establece, de forma análoga, que podrá interponer la correspondiente reclamación toda persona física o jurídica cuyos derechos o intereses legítimos se hayan visto perjudicados o puedan resultar afectados por las decisiones objeto de reclamación.

\section{MEDIDAS CAUTELARES}

\section{A) Solicitud antes de la interposición del recurso especial y lugar de presentación}

El art. $313^{20}$ y de forma análoga el art. 103 de la Ley 31/2007) regulan la solicitud de "medidas cautelares de carácter provisional" o si se prefiere "medidas provisionalísimas" atendida la naturaleza de las mismas, ya que se pueden solicitar antes de la interposición del recurso especial, lo que recuerda a las contempladas en el art. 133 de la LJCA/1998.

En este sentido, cabe destacar que el apartado 1 del Art. 313 establece que "antes de interponer el recurso especial regulado en este Libro, las personas físicas y ju-

19 Hoy art. 42 del TRCSP (RDLegislativo 3/2011, de 14 de noviembre)

20 Hoy artículo 43 del TRCSP (RDLegisltivo 3/2011, de 14 de noviembre). 
rídicas, legitimadas ex Art. 312, podrán solicitar ante el órgano competente para resolver el recurso la adopción de medidas provisionales.

\section{B) Objeto: corrección de infracciones de procedimiento o de evitación de otos perjuicios a los intereses de los afectados, incluyendo la suspensión del procedimiento de adjudicación del contrato}

El objeto de tales medidas provisionales va dirigido, según el inciso segundo del apartado primero del Art. 312 (recuérdese nuevo art 42 del TRCSP), a corregir infracciones de procedimiento o impedir que se causen otros perjuicios a los intereses afectados, y podrán estar incluidas, entre ellas, las destinadas a suspender o a hacer que se suspenda el procedimiento de adjudicación del contrato en cuestión o la ejecución de cualquier decisión adoptada por los órganos de contratación.

\section{C) Plazo de resolución}

El órgano competente para resolver el recurso deberá adoptar decisión en forma motivada sobre las medidas provisionales dentro de los cinco días hábiles siguientes, a la presentación del escrito en que se soliciten.

\section{D) Tramitación}

La tramitación del escrito de solicitud de medidas provisionales comporta, que el órgano decisorio, en el mismo día en que se reciba la petición de la medida provisional, comunicará la misma al órgano de contratación, que dispondrá de un plazo de dos días hábiles, para presentar las alegaciones que considere oportunas referidas a la adopción de las medidas solicitadas o a las propuestas por el propio órgano decisorio. Si transcurrido este plazo no se formulasen alegaciones se continuará el procedimiento.

\section{E) Resolución de la solicitud de las medidas cautelares y efectos}

La resolución de la solicitud de medidas cautelares, deberá adoptarse de forma motivada.

Si antes de dictar resolución se hubiese interpuesto el recurso, el órgano decisorio acumulará a éste la solicitud de medidas provisionales y resolverá sobre ellas en la forma prevista en el artículo $316^{21}$.

21 La referencia debe entenderse realizada al nuevo art. 46 TRCSP (RDLegislativo 3/2011, de 14 de noviembre) 
El apartado 4 del Art. 313 (nuevo art. 43.4 del TRCSP) dispone que la suspensión del procedimiento que pueda acordarse cautelarmente no afectará, en ningún caso, al plazo concedido para la presentación de ofertas o proposiciones por los interesados.

Finalmente el apartado 5 del Art. 313 (nuevo art. 43.5 del TRCSP) establece que las medidas provisionales que se soliciten y acuerden con anterioridad a la presentación del recurso especial en materia de contratación decaerán una vez transcurra el plazo establecido para su interposición sin que el interesado lo haya deducido, esto es que las medidas cautelares van vinculadas a la interposición del recurso especial, aunque su tramitación se lleve con anterioridad tal como se ha expuesto.

\section{F) Recurso contra la resolución de adopción de medidas cautelares}

Contra las resoluciones dictadas en este procedimiento no cabrá recurso alguno, según establece el Art. 313.2 in fine (nuevo art. 43.2 TRCSP), "sin perjuicio de los que procedan contra las resoluciones que se dicten en el procedimiento principal.

\section{G) Caución}

El apartado 3 del Art. 313 (nuevo art. 43.2 TRCSP)establece que cuando de la adopción de las medidas provisionales puedan derivarse perjuicios de cualquier naturaleza, la resolución podrá imponer la constitución de caución o garantía suficiente para responder de ellos, sin que aquéllas produzcan efectos hasta que dicha caución o garantía sea constituida.

Reglamentariamente se determinará la cuantía y forma de la garantía a constituir así como los requisitos para su devolución.

\section{LA CUESTIÓN DE NULIDAD: LOS SUPUESTOS ESPECIALES DE NULIDAD CONTRACTUAL}

\section{A) La Directiva 2007/66/CE como inspiradora de la Reforma de la legislación de Contratos públicos}

Como expusimos más arriba, la supresión del capítulo VI del título I del Libro primero de la Ley $3 / 2007$, y su modificación por la creación de la Sección Segunda del Capítulo V del Título I del Libro Primero con el rótulo "Supuestos especiales de nulidad" comprendiendo los artículos 37, 38 y 39 de la misma, trae causa, por un lado por la necesidad de dar respuesta al expediente incoado por la Comisión europea tras la STJUE de 3 de abril de 2008 y de otro, por transponer la Directiva 2007/66/CE.

Como señala el Dictamen del Consejo de Estado de 29 de abril de 2010. 
“La Directiva 2007/66/CE contempla diversos supuestos de "ineficacia" de los contratos ya celebrados (artículo 2 quinquies de las Directivas 89/665/CEE y 92/13/ CEE). El objetivo que se persigue con esta regulación -según indica el considerando (21) - es que ante determinadas infracciones, que se consideran especialmente graves, "los derechos y las obligaciones de las partes del contrato dejen de ser de obligado cumplimiento y ejecución", correspondiendo a las legislaciones nacionales la determinación de las consecuencias derivadas de dicha ineficacia.

Esta acción se contempla, en primer lugar, para aquellos casos en que el poder adjudicador ha adjudicado un contrato sin publicar previamente un anuncio de licitación en el D.O.U.E. siendo esta publicación obligatoria. Se contemplan, no obstante, las siguientes excepciones:

- Cuando el poder adjudicador considera que la adjudicación de un contrato sin publicación previa de un anuncio se puede admitir de conformidad con la Directiva 2004/18/CE.

- Cuando el poder adjudicador ha publicado en el D.O.U.E. un anuncio con determinada información (nombre y datos de contacto del poder adjudicador; descripción de la finalidad del contrato; justificación de la decisión del poder adjudicador de conceder el contrato sin la publicación previa de un anuncio de licitación en el D.O.U.E.; nombre y datos de contacto del operador económico a favor de quien se haya adoptado una decisión de adjudicación del contrato; y, en su caso, cualquier otra información que el poder adjudicador considere útil.

- Cuando el contrato no se ha celebrado hasta transcurridos al menos diez días civiles a partir del día siguiente a la fecha de publicación de dicho anuncio.

El segundo supuesto en el que cabe esta acción es en caso de infracción de la obligación de suspender cuando se exija recurso previo ante el órgano de contratación, de celebración del contrato antes de que se haya resuelto el recurso o tomado una decisión sobre la solicitud de medidas provisionales o de falta de remisión de la información requerida, si dicha infracción privó al licitador que interpuso recurso de la posibilidad de ejercitar recursos precontractuales o afectó a las posibilidades de resultar adjudicatario del contrato.

Finalmente, también procede en los supuestos mencionados en el segundo párrafo de la letra c) del artículo 2 ter, si los Estados miembros se han acogido a la excepción del plazo suspensivo para contratos basados en un acuerdo marco y un sistema dinámico de adquisición. En este caso también se contemplan una serie de excepciones: si se considera que la adjudicación de un contrato es conforme a la Directiva 2004/18/CE; si se remitió a los licitadores afectados una decisión de adjudicación del contrato junto con la exposición resumida de las razones en que se basa la adjudica80 ción; y si el contrato no se ha celebrado hasta transcurrido el plazo de suspensión. 
Este recurso ha de interponerse, según lo establecido en el artículo 2 septies, antes de que transcurran treinta días desde la publicación del anuncio de adjudicación del contrato o desde que se haya facilitado la información exigida y, en todo caso, antes de que transcurran seis meses a partir del día siguiente a la fecha de celebración del contrato.

Los efectos de la declaración de ineficacia quedan a la determinación de los Estados miembros. En tal sentido, se señala que se podrá establecer la anulación con efectos retroactivos de todas las obligaciones contractuales o limitar el alcance de la anulación a las obligaciones que estén aún por ejecutar (previéndose, en este último caso, la imposición de multa o la reducción de la duración del contrato).

Por último, se contempla la posibilidad de no declarar la nulidad de un contrato, aunque haya sido adjudicado ilegalmente, si el órgano independiente de recurso considera que razones imperiosas de interés general exigen mantener los efectos del contrato. En tal caso, se prevé la imposición de sanciones alternativas (artículo 2 quinquies.3, en relación con artículo 2 sexies).

\section{B) La modificación de las leyes 30/2007 (Artículos 37 a 39) 22 y 31/2007 (Artículos 109 a 111).}

\section{a) Su transposición al Derecho interno: alcance}

Como señalábamos más arriba, la transposición de los preceptos aludidos de la Directiva 2007/66/CE que se acaban de exponer se aborda en la nueva sección segunda del capítulo V del título I del Libro I de la Ley 30/2007, comprensiva de los artículos 37 a 39, a los que se da nueva redacción (apartados uno y dos del artículo primero del anteproyecto). En el caso de la Ley 31/2007 la incorporación se lleva a efecto en el capítulo II del título VII, comprensivo de los artículos 109 a 111 (apartados tres y cuatro del artículo segundo del anteproyecto).

El alcance de la transposición realizada de la Directiva 2007/66/CE realizada por la Ley 34/2010, de 5 de agosto, en este punto no generó rechazo alguno en su momento por el Consejo de estado, al dictaminar sobre el Anteproyecto.

En tal sentido cabe recordar que el alto cuerpo consultivo del gobierno, señaló lo siguiente:

"Como ha señalado el Consejo de Estado en diversas ocasiones, a la hora de abordar la tarea de incorporar el Derecho comunitario ( $y$, en especial, las directivas), lo más razonable es intentar dar una redacción clara y técnicamente correcta a la norma de transposición (entre otros, dictámenes del Consejo de Estado 426/91, de 
11 de abril, 1684/91, de 26 de diciembre, 380/92, de 26 de marzo, 271/92, de 9 de abril, y $1.429 / 2005$, de 20 de octubre), lo cual es especialmente conveniente cuando se acude a categorías jurídicas que carecen de equivalente en el ordenamiento interno. Desde esta perspectiva, se valora positivamente, sin perjuicio de las observaciones que más adelante se formulan sobre esta cuestión, el esfuerzo realizado para tratar de encajar, dentro de las categorías jurídicas internas, los supuestos de ineficacia contractual contemplados en la Directiva 2007/66/CE.

En otros aspectos, sin embargo, la transposición realizada puede resultar en exceso vinculada al tenor literal de la Directiva (por ejemplo, al mantener expresiones como "razones imperiosas de interés general", que, aunque es cierto que tiene un significado preciso en el ámbito comunitario, podrían ser sustituidas por otras de más raigambre en la tradición jurídica española) e incluso al orden sistemático empleado por la norma comunitaria (pues un mejor orden lógico iniciaría el articulado con la determinación de los supuestos especiales de nulidad, continuaría con los aspectos procedimentales y finalizaría con las consecuencias jurídicas de la declaración de nulidad).

No hay que desconocer, sin embargo, el especial rigor con que la Comisión Europea viene controlando la transposición de la normativa comunitaria sobre contratación pública; de ahí que la opción por la transcripción literal pueda en ocasiones encontrar su justificación en evitar que la utilización de otra terminología sea semillero de conflictos y eventual fundamento de alguna imputación de infracción del Derecho comunitario".

\title{
b) Los supuestos de nulidad contractual en el art. 37 de la Ley $30 / 2007^{23}$
}

\author{
El Artículo 37 de la ley 30/2007, regula los nuevos supuestos de nulidad con- \\ tractual.
}

\section{Contratos susceptibles de ser declarados nulos}

El apartado 1 del Art. 37 dispone que serán susceptibles de ser declarados nulos los contratos sujetos a regulación armonizada a que se refieren los artículos 13 a 17, ambos inclusive, de la Ley 30/207, así como los contratos de servicios comprendidos en las categorías 17 a 27 del Anexo II cuyo valor estimado sea igual o superior a 193.000 euros serán nulos en los siguientes casos:

Los supuestos de nulidad son lo siguientes:

a) Cuando el contrato se haya adjudicado sin cumplir previamente con el requisito de publicación del anuncio de licitación en el Diario Oficial de la Unión Europea,

23 EI TRCSP (RDLegislativo 3/2011, de 14 de noviembre, no ha alterado la numeración de la regulación de los supuestos de nulidad contractual, que continúan siendo los articulo 37 al 39 del mencionado Texto Refundido. 
en aquellos casos en que sea preceptivo, de conformidad con el artículo 126 (hoy articulo 142 del TRCSP).

b) Cuando no se hubiese respetado el plazo de quince días hábiles previsto en el artículo 140.3 para la formalización del contrato siempre que concurran los dos siguientes requisitos:

$1^{\circ}$ ) Que por esta causa el licitador se hubiese visto privado de la posibilidad de interponer el recurso regulado en los artículos 310 (nuevo art. 40 TRCSP) y siguientes $y$,

$2^{\circ}$ ) Que, además, concurra alguna infracción de los preceptos que regulan el procedimiento de adjudicación de los contratos que le hubiera impedido obtener ésta.

c) Cuando a pesar de haberse interpuesto el recurso especial en materia de contratación a que se refieren los artículos 310 y siguientes, se lleve a efecto la formalización del contrato sin tener en cuenta la suspensión automática del acto de adjudicación en los casos en que fuera procedente, y sin esperar a que el órgano independiente hubiese dictado resolución sobre el mantenimiento o no de la suspensión del acto recurrido.

Dictamen Consejo de Estado, de 29 de abril de 2010:

"A la hora de definir las infracciones que pueden dar lugar a la nulidad de los contratos, la letra c) del artículo 37.1 de la Ley 30/2007 se refiere al siguiente supuesto: "Cuando a pesar de haberse interpuesto el recurso especial en materia de contratación a que se refieren los artículos 10 y siguientes, se lleve a efecto la formalización del contrato sin tener en cuenta la suspensión automática del acto de adjudicación en los casos en que fuera procedente, y sin esperar a que el órgano independiente hubiese dictado resolución sobre el mantenimiento o no de la suspensión del acto recurrido".

De otra parte, al definirse las circunstancias que han de concurrir para que no proceda la declaración de nulidad en los supuestos contemplados en las letras d) y e) del apartado 1 del artículo 37, se exige "que el contrato no se perfeccione hasta transcurridos diez días hábiles desde el siguiente al de la recepción de la notificación a (sic) los licitadores afectados".

Nuevamente, se plantea la opción entre las dos modalidades de cómputo del plazo que contempla la Directiva 2007/66/CE (en este caso, el último guión del apartado 5 del artículo 2 quinquies de la Directiva de recursos); y se opta por el criterio de la recepción de la notificación por los licitadores afectados.

En línea con la observación formulada con anterioridad, se recuerda la conveniencia de que, en la medida de lo posible, se fijen unos plazos y un criterio de cómputo 
similares. De ahí que quizá fuera preferible optar por fijar un plazo de quince días y considerar como inicio del cómputo la remisión de la notificación a los licitadores, lo que permitiría, además, considerar el mismo dies a quo para todas las notificaciones".

d) Tratándose de un contrato basado en un acuerdo marco del artículo 180 celebrado con varios empresarios que por su valor estimado deba ser considerado sujeto a regulación armonizada, si se hubieran incumplido las normas sobre adjudicación establecidas en párrafo segundo del artículo 182.4.

e) Cuando se trate de la adjudicación de un contrato específico basado en un sistema dinámico de contratación en el que estuviesen admitidos varios empresarios, siempre que el contrato a adjudicar esté sujeto a regulación armonizada y se hubieran incumplido las normas establecidas en el artículo 186 sobre adjudicación de tales contratos.

\section{Excepciones}

El apartado 2 del Art. 37, señala en línea con lo establecido por la Directiva $2007 / 66 / C E$, establece una serie de excepciones, en primer lugar, en relación con el requisitos de publicidad de los Contratos (Art. 37.1 a), previa a su adjudicación sin cumplir con el requisito de publicación del anuncio de licitación en el Diario Oficial de la Unión Europea, en aquellos casos en que sea preceptivo.

Las excepciones señaladas son las tres siguientes:

a) Que de conformidad con el criterio del órgano de contratación el contrato esté incluido en alguno de los supuestos de exención de publicación del anuncio de licitación en el Diario Oficial de la Unión Europea previstos en esta Ley.

b) Que el órgano de contratación publique en el Diario Oficial de la Unión Europea un anuncio de transparencia previa voluntaria en el que se manifieste su intención de celebrar el contrato y que contenga los siguientes extremos:

— identificación del órgano de contratación

— descripción de la finalidad del contrato

— justificación de la decisión de adjudicar el contrato sin el requisito de publicación del artículo 126

— identificación del adjudicatario del contrato

84 - cualquier otra información que el órgano de contratación considere relevante 
c) Que el contrato no se haya perfeccionado hasta transcurridos diez días hábiles a contar desde el siguiente al de publicación del anuncio.

La segunda excepción se contempla en el apartado 3 del Art. 37 y se refiere a los supuestos regulados en las letras d) y e), (contrato basado en un acuerdo marco del artículo 180 y contrato específico basado en un sistema dinámico de contratación) si concurren conjuntamente las dos condiciones siguientes:

a) Que el órgano de contratación haya notificado a todos los licitadores afectados la adjudicación del contrato y, si lo solicitan, los motivos del rechazo de su candidatura o de su proposición y de las características de la proposición del adjudicatario que fueron determinantes de la adjudicación a su favor, sin perjuicio de lo dispuesto en el artículo 137 en cuanto a los datos cuya comunicación no fuera procedente.

b) Que el contrato no se hubiera perfeccionado hasta transcurridos quince días hábiles desde el siguiente al de la remisión de la notificación a los licitadores afectados.

\section{c) Los supuestos de nulidad contractual en el articulo 109 de la Ley 31/2007}

1. Los supuestos del Art. 109.1 de la Ley 31/2007

El Art. 109.1 de la Ley 31/2007 establece, de forma análoga al Art. 37 de la Ley 30/2007, las causas de nulidad respecto a los contratos celebrados de conformidad con lo dispuesto en esta Ley:

Estas son las siguientes:

a) Cuando el contrato se haya adjudicado sin cumplir previamente con el requisito de publicación del anuncio de licitación en el "Diario Oficial de la Unión Europea”, en la forma prevista en el artículo 65.

b) Cuando a pesar de haberse interpuesto una reclamación por infracción de las normas de esta Ley, se hubiese formalizado el contrato sin tener en cuenta la suspensión automática del acto de adjudicación en los casos en que fuera procedente, y sin esperar a que se dicte resolución sobre el mantenimiento o no de la suspensión del acto recurrido.

Dictamen Consejo de Estado, de 29 de abril de 2010:

"A la hora de definir las infracciones que pueden dar lugar a la nulidad de los contratos, la letra c) del artículo 37.1 de la Ley 30/2007 se refiere al siguiente supuesto: "Cuando a pesar de haberse interpuesto el recurso especial en materia de con- 
tratación a que se refieren los artículos 10 y siguientes, se lleve a efecto la formalización del contrato sin tener en cuenta la suspensión automática del acto de adjudicación en los casos en que fuera procedente, y sin esperar a que el órgano independiente hubiese dictado resolución sobre el mantenimiento o no de la suspensión del acto recurrido".

La previsión equivalente en el marco de la Ley 31/2007 se encuentra recogida en la letra b) del apartado 1 del proyectado artículo 109. Sin embargo, en ella no se recoge el supuesto de que la formalización se lleve a efecto sin tener en cuenta la suspensión automática del acto de adjudicación.

Puesto que la regla de la suspensión automática se recoge en el apartado 5 de la nueva redacción del artículo 104 de la misma Ley, debe completarse la letra b) del artículo 109.1 en el sentido indicado.

De otra parte, al definirse las circunstancias que han de concurrir para que no proceda la declaración de nulidad en los supuestos contemplados en las letras d) y e) del apartado 1 del artículo 37, se exige "que el contrato no se perfeccione hasta transcurridos diez días hábiles desde el siguiente al de la recepción de la notificación a (sic) los licitadores afectados".

Nuevamente, se plantea la opción entre las dos modalidades de cómputo del plazo que contempla la Directiva 2007/66/CE (en este caso, el último guión del apartado 5 del artículo 2 quinquies de la Directiva de recursos); y se opta por el criterio de la recepción de la notificación por los licitadores afectados.

En línea con la observación formulada con anterioridad, se recuerda la conveniencia de que, en la medida de lo posible, se fijen unos plazos y un criterio de cómputo similares. De ahí que quizá fuera preferible optar por fijar un plazo de quince días y considerar como inicio del cómputo la remisión de la notificación a los licitadores, lo que permitiría, además, considerar el mismo dies a quo para todas las notificaciones.

Esta misma observación es trasladable a la redacción proyectada para el artículo 109.3.b) de la Ley 31/2007".

c) Cuando no se hubiese respetado el plazo de quince días hábiles previsto en el artículo 83.3 antes de proceder a la formalización del contrato siempre que por esta causa el licitador se hubiese visto privado de la posibilidad de interponer el recurso regulado en los artículos 101 y siguientes y, además, hubiera concurrido con alguna infracción de los preceptos que regulan el procedimiento de adjudicación de los contratos que le hubiera impedido obtener ésta.

A la hora de definir las infracciones que pueden dar lugar a la nulidad de los contratos, la letra c) del artículo 37.1 de la Ley 30/2007 se refiere al siguiente supuesto: "Cuan86 do a pesar de haberse interpuesto el recurso especial en materia de contratación a que 
se refieren los artículos 10 y siguientes, se lleve a efecto la formalización del contrato sin tener en cuenta la suspensión automática del acto de adjudicación en los casos en que fuera procedente, y sin esperar a que el órgano independiente hubiese dictado resolución sobre el mantenimiento o no de la suspensión del acto recurrido".

La previsión equivalente en el marco de la Ley 31/2007 se encuentra recogida en la letra b) del apartado 1 del proyectado artículo 109. Sin embargo, en ella no se recoge el supuesto de que la formalización se lleve a efecto sin tener en cuenta la suspensión automática del acto de adjudicación.

Puesto que la regla de la suspensión automática se recoge en el apartado 5 de la nueva redacción del artículo 104 de la misma Ley, debe completarse la letra b) del artículo 109.1 en el sentido indicado.

De otra parte, al definirse las circunstancias que han de concurrir para que no proceda la declaración de nulidad en los supuestos contemplados en las letras d) y e) del apartado 1 del artículo 37, se exige "que el contrato no se perfeccione hasta transcurridos diez días hábiles desde el siguiente al de la recepción de la notificación a (sic) los licitadores afectados".

Nuevamente, se plantea la opción entre las dos modalidades de cómputo del plazo que contempla la Directiva 2007/66/CE (en este caso, el último guión del apartado 5 del artículo 2 quinquies de la Directiva de recursos); y se opta por el criterio de la recepción de la notificación por los licitadores afectados.

En línea con la observación formulada con anterioridad, se recuerda la conveniencia de que, en la medida de lo posible, se fijen unos plazos y un criterio de cómputo similares. De ahí que quizá fuera preferible optar por fijar un plazo de quince días y considerar como inicio del cómputo la remisión de la notificación a los licitadores, lo que permitiría, además, considerar el mismo dies a quo para todas las notificaciones.

Esta misma observación es trasladable a la redacción proyectada para el artículo 109.3.b) de la Ley 31/2007.

d) Cuando se trate de la adjudicación de un contrato específico basado en un sistema dinámico de contratación en el que estuviesen admitidos varios empresarios, siempre que el contrato a adjudicar tenga un importe superior a los umbrales establecidos en el artículo 16 y se hubieran incumplido las normas sobre adjudicación de tales contratos establecidas en el artículo 46.

\section{Excepciones}

El apartado 2 del Art. 109 señala las excepciones siguientes en relación con la causa de nulidad de publicidad de los Contratos (Art. 37.1 a), previa a su adjudicación, 
sin cumplir con el requisito de publicación del anuncio de licitación en el Diario Oficial de la Unión Europea, en aquellos casos en que sea preceptivo:

a) Que de conformidad con el criterio de la entidad contratante el contrato esté incluido en alguno de los supuestos de exención de publicación del anuncio de licitación en el Diario Oficial de la Unión Europea previstos en esta Ley.

b) Que el órgano de contratación publique en el Diario Oficial de la Unión Europea un anuncio de transparencia previa voluntaria en el que se manifieste su intención de celebrar el contrato y que contenga los siguientes extremos:

— identificación del órgano de contratación

- descripción de la finalidad del contrato

— justificación de la decisión de adjudicar el contrato sin el requisito de publicación

— identificación del adjudicatario del contrato

— cualquier otra información que el órgano de contratación considere relevante

c) Que el contrato no se haya formalizado hasta transcurridos diez días hábiles desde la publicación del anuncio.

De igual modo, el apartado 3 del art. 109 establece en relación con los la causa de nulidad contratos de la letra d) [adjudicación de un contrato específico basado en un sistema dinámico de contratación] si concurren conjuntamente las dos condiciones siguientes:

a) Que el órgano de contratación haya notificado a todos los licitadores afectados la adjudicación del contrato y, si lo solicitan, los motivos del rechazo de su candidatura o de su proposición y de las características de la proposición del adjudicatario que fueron determinantes de la adjudicación a su favor, sin perjuicio lo dispuesto en el artículo 20.2 en cuanto a los datos cuya comunicación no fuera procedente.

b) Que el contrato no se hubiera celebrado hasta transcurridos quince días hábiles contados desde el siguiente al de la remisión de la notificación a los licitadores afectados.

\section{C) La atribución de la resolución de los supuestos especiales de nulidad al Tribunal Administrativo Central de Recursos Contractuales}

88 Administrativo Central de Recurso contractuales, la resolución de las causas de nulidad. 
El Art. 39 señala que la interposición de la cuestión de nulidad, en los casos a que se refiere el artículo 37.1, deberá plantearse ante el órgano previsto en el artículo 311 (hoy articulo. 41 del nuevo TRCSP) que será el competente para tramitar el procedimiento y resolverla. En términos similares se expresa, el Art. 111.1 al disponer que cuestión de nulidad deberá plantearse ante el órgano previsto en el artículo 101 (TACRECO) que será el competente para tramitar el procedimiento y resolverla.

La atribución al Tribunal administrativo Central de Recursos contractuales del conocimiento de la cuestión de nulidad era una exigencia derivada dela STJUE, que no admitía el criterio del antiguo Art. 37 de la Ley 30/2007. A ello obedece, como sabemos, la remisión que los arts. 39. 1 de la Ley 30/2007 y 111.1 31/2007 hacen a dicho TACRECO que el Art. 311 crea de nueva planta.

No obstante lo cual, la regulación de la cuestión de nulidad ex Art. 37 y siguientes plantea problemas de delimitación con los supuestos de nulidad ex Art. 310 y siguientes, por lo que se hace necesario examinar el alcance y naturaleza de esta cuestión de nulidad.

\section{D) Naturaleza de la acción}

La determinación de la naturaleza de la acción de nulidad ex art. 37.1 viene caracterizada por la calificación que la Directiva 2007/66/CE hace al hablar de "ineficacia" de los contratos en un sentido y con un alcance que como señala el Consejo de Estado no es el que habitualmente se atribuye a ese termino en Derecho español.

El Consejo señala, por dicho razón, que la norma ahora transpuesta a Derecho interno (español) incurre en ciertas contradicciones.

Veamos, pues, el razonar del Alto Cuerpo consultivo:

“El apartado 1 del proyectado artículo 37 de la Ley 30/2007 establece los casos en que determinados contratos "serán nulos de pleno derecho". En cambio, el apartado 1 del proyectado artículo 109 de la Ley 31/2007 dice que los contratos "serán nulos".

La nulidad de pleno derecho, entendida como la máxima sanción que el ordenamiento preceptúa, opera ipso iure, tiene eficacia retroactiva y es definitiva (sin que quepa la convalidación). Por ello, no resulta correcta la afirmación de que los contratos definidos en el apartado 1 del artículo 37.1 de la Ley 30/2007 serán nulos de pleno derecho. Pues dicha categoría no se compadece bien con algunos de los aspectos del régimen jurídico diseñado a continuación y, especialmente, con la posibilidad de mantener los efectos del contrato (artículo 38) y con la introducción de unos plazos para interponer la cuestión de nulidad (artículo 39). Sería menos confuso decir que los contratos serán declarados nulos o serán nulos, de forma análoga a la modificación operada en la Ley 31/2007. 
Con todo, ha de llamarse la atención sobre las singulares características de la ineficacia regulada en la Directiva 2007/66/CE, que dan lugar a la configuración de un supuesto con perfiles propios, con alguna nota característica de la nulidad de pleno derecho, pero en líneas generales más próximo a la figura de la anulabilidad. Baste señalar, por ejemplo, que las causas de nulidad están tasadas en la norma legal, que la propia Ley define posibles excepciones, que cabe la posibilidad de sustituir la declaración de nulidad por la imposición de sanciones alternativas y que la cuestión de nulidad debe interponerse dentro del plazo señalado al efecto.

La advertencia del Consejo de Estado la nulidad de pleno derecho que se predicaba en el texto del Anteproyecto, ha sido recogida en la redacción final del Art. 37.1 de la Ley 30/2007, que declara que..los "contratos serán nulos".

Todo lo cual permite concluir, de la mano de las consideraciones del Consejo de Estado que dichos preceptos introducen una suerte de "nulidad comunitaria". Es cierto que las categorías de nulidad de pleno derecho y anulabilidad están muy asentadas en nuestro ordenamiento, constituyendo un precipitado dogmático que no siempre tiene una traducción practica tan categórica por la acción moderada y prudencial de los Tribunales de Justicia. Pero si es lo cierto que más allá de lo expuesto, no deja de tener que tipologizarse, en el ámbito del Derecho administrativo este nuevo supuesto de nulidad limitada, a medio camino entre la nulidad de pleno derecho y la anulabilidad, cuyas consecuencias jurídicas las abordaremos más adelante.

\section{E) La delimitación de los contratos objeto de impugnación por las vías del recurso especial y de la cuestión de nulidad}

a) La posición del Consejo de Estado favorable a una inclusión del contrato de gestión de servicios en los que el presupuesto de gastos de primer establecimiento excluido el IVA, sea superior a 500.000 euros y el plazo de duración superior a 5 años.

Llamábamos más arriba la atención sobre el ámbito de aplicación o delimitación de los contratos objeto de recursos ante el TACRECO por las dos vías de recurso que la reforma de la Ley 34/200, introduce.

Esta observación es también destacada por el Consejo de Estado, que dictaminó lo que sigue:

"La redacción proyectada de los artículos 37.1 (cuestión de nulidad) y 310.1 (recurso especial) de la Ley 30/2007 es muy similar a la hora de determinar los contratos a los que resultan de aplicación sus previsiones. El artículo 37.1 delimita su ámbito de aplicación por referencia a los contratos sujetos a regulación armonizada previstos en los artículos 9017 a 27 del anexo II cuyo valor estimado sea igual o superior a 193.000 euros. 
Por su parte, el proyectado artículo 310.1 se refiere a: 1) los contratos de obras, concesión de obras públicas, de suministro, de servicios, de colaboración entre el sector público y el sector privado y acuerdos marco sujetos a regulación armonizada; 2) contratos de servicios comprendidos en las categorías 17 a 27 del anexo II cuyo valor estimado sea igual o superior a 193.000 euros; y contratos de gestión de servicios públicos en los que el presupuesto de gastos de primer establecimiento, excluido el IVA, sea superior a 500.000 euros y el plazo de duración superior a cinco años.

Parece razonable hacer coincidir los ámbitos materiales de una y otra figura. En este sentido y a falta de una explicación acerca de cuál ha sido el criterio empleado para delimitar ambos supuestos, debiera incluirse en el artículo 37.1 el supuesto de los contratos de gestión de servicios públicos en los que el presupuesto de gastos de primer establecimiento, excluido el IVA, sea superior a 500.000 euros y el plazo de duración superior a 5 años.

De otra parte, sería conveniente introducir alguna regla con la finalidad de resolver la compatibilidad o incompatibilidad entre la cuestión de nulidad y el recurso especial.

b) La delimitación de los planos impugnatorios de la cuestión y el recurso especial: ¿compatibilidad o preclusión?: remisión al procedimiento. El ejemplo francés: los nuevos artículos L.551-13 a 551-23 del Código de Justicia Administrativa y el référé contractuel.

El Consejo de Estado llama la atención sobre la regulación de esta cuestión en Derecho Administrativo francés.

En tal sentido señala que:

“En el caso francés, por ejemplo, la articulación de estos supuestos (que se lleva a efecto en los nuevos artículos L.551-13 a 551-23 del Código de Justicia Administrativa) se hace mediante la creación de un référé contractuel, a través del cual el órgano judicial se pronuncia sobre la nulidad del contrato, entre otros supuestos, cuando alguna de las medidas de publicidad requeridas para su adjudicación no se ha adoptado o cuando se ha omitido una publicación en el D.O.U.E. cuando fuera preceptiva. Y se establece que dicho recurso no está abierto al recurrente que haya hecho uso del référé précontractuel cuando el poder adjudicador haya respetado la suspensión y haya acatado la resolución recaída"

\section{F) El procedimiento para entablar la cuestión de nulidad ex Art. 37.1 de la Ley 30/2007 y 111 de la Ley 31/2007}

\section{a) Legitimados}

El apartado 2 del Art. 39 de la ley 30/2007 (articulo 39.2 en el TRCSP) y 111.2 de la ley 31/2007, establecen que podrá plantear la cuestión de nulidad, en tales casos, 
toda persona física o jurídica cuyos derechos o intereses legítimos se hayan visto perjudicados o puedan resultar afectados por los supuestos de nulidad del artículo 37 (RDL 3/2011) o 109 (Art. 31/2007).

\section{b) Trámite de admisión}

Siguiendo la recomendación del Consejo de Estado, el TACRECO podrá inadmitir la cuestión de nulidad cuando el interesado hubiera interpuesto recurso especial regulado en los artículos 310 y siguientes (art 40 del TRCSP) sobre el mismo acto habiendo respetado el órgano de contratación la suspensión del acto impugnado y la resolución dictada.

(Arts 39.2 Ley 30/2007 y 111.2 de la Ley 31/2007)

\section{c) Plazo impugnatorio}

El apartado 3 del Art. $39^{24}$ dispone que el plazo para la interposición de la cuestión de nulidad será de treinta días hábiles a contar:

a) desde la publicación de la adjudicación del contrato en la forma prevista en el artículo 138.2, incluyendo las razones justificativas de la no publicación de la licitación en el Diario Oficial de la Unión Europea,

b) o desde la notificación a los licitadores afectados, de los motivos del rechazo de su candidatura o de su proposición y de las características de la proposición del adjudicatario que fueron determinantes de la adjudicación a su favor, sin perjuicio de lo dispuesto en el artículo 137 en cuanto a los datos cuya comunicación no fuera procedente.

Fuera de los casos previstos en el apartado 3, el apartado 4 precisa que la cuestión de nulidad deberá interponerse antes de que transcurran seis meses a contar desde la formalización del contrato.

(En el mismo sentido los articulo 111.3 y 4 de la Ley 31/2007)

\section{d) Tramitación}

El apartado 5 del art. 39 dispone que la cuestión de nulidad se tramitará de conformidad con lo dispuesto en los artículos 314 y siguientes, es decir el procedimiento relativo al recurso especial, con las siguientes salvedades: 
a) No será de aplicación lo dispuesto en el artículo 314.1 en cuanto a la exigencia de anunciar la interposición del recurso.

b) La interposición de la cuestión de nulidad no producirá efectos suspensivos de ninguna clase por sí sola.

c) El plazo establecido en el artículo 313.2, párrafo segundo y en el 316.3 para que el órgano de contratación formule alegaciones en relación con la solicitud de medidas cautelares se elevará a siete días hábiles.

d) El plazo establecido en el artículo 316.2 para la remisión del expediente por el órgano de contratación, acompañado del correspondiente informe, se elevará a siete días hábiles.

\section{e) Resolución y sanciones alternativas: solicitud por el órgano de contratación. Incidente de ejecución de la resolución}

El apartado 5, letra e) del art. 39 establece que en la resolución de la cuestión de nulidad, el órgano competente para dictarla deberá resolver también sobre la procedencia de aplicar las sanciones alternativas si el órgano de contratación lo hubiera solicitado en el informe que debe acompañar la remisión del expediente administrativo.

Sin no lo hubiese solicitado el órgano de contratación en la forma señalada en el apartado 5 e), la aplicación de las sanciones puede llevarse a cabo en el trámite de ejecución de la resolución. (Art 39.5 e)

En tal caso el órgano competente, se abre un incidente de ejecución de la resolución en la que previa audiencia por plazo de cinco días a las partes comparecidas en el procedimiento, resolverá sobre la procedencia o no de aplicar la sanción alternativa solicitada dentro de los cinco días siguientes al transcurso del plazo anterior.

Contra esta resolución cabrá interponer recurso en los mismos términos previstos para las resoluciones dictadas resolviendo sobre el fondo, esto es ante los órganos competentes de la jurisdicción contencioso-administrativa.

G) El art. 38 de la Ley $30 / 2007^{25}$ y las consecuencias derivadas de la declaración de nulidad

\section{a) Efectos de la declaración de nulidad}

Las consecuencias jurídicas de la declaración de nulidad son abordadas, por un lado, en el nuevo art. 38 de la Ley 30/2007 y, de otro, en el art. 110 de la Ley 31/2007.

25 Sigue siendo el art. 38 en el TRCSP (RDLegislativo 3/2011, de 14 de noviembre) 
En primer lugar, el apartado 1 del art. 38 de la Ley 30/2007 establecen que la declaración de nulidad por las causas previstas en el artículo anterior producirá los efectos establecidos en el artículo 35.1 de esta Ley.

El mencionado art. 35.1 de la Ley 30/2007 de nueva redacción también por la ley $34 / 2010$, señala que la declaración de nulidad de los actos preparatorios del contrato o de la adjudicación, cuando sea firme, llevará en todo caso consigo la del mismo contrato, que entrará en fase de liquidación, debiendo restituirse las partes recíprocamente las cosas que hubiesen recibido en virtud del mismo y si esto no fuese posible se devolverá su valor. La parte que resulte culpable deberá indemnizar a la contraria de los daños y perjuicios que haya sufrido."

Estos son por tanto, los efectos nucleares de la declaración de nulidad,: liquidación del contrato con restitución recíproca de las cosas recibidas (precios y obra, servicio etc) y la indemnización por la parte culpable de la indemnización de daños y perjuicios que la contraparte hubiese sufrido.

El art. 110.1 de la Ley 30/2007 introduce alguna variante respecto a las consecuencias de la ley 30/2007, al establecer expresamente que las “consecuencias jurídicas de la declaración de nulidad por las causas previstas en el artículo 109 se determinarán por el órgano que la acuerde quien podrá declarar la nulidad de pleno derecho o limitar el alcance de la anulación a las obligaciones que estén aún por ejecutar. En este último supuesto, se estará a lo establecido en el apartado siguiente en cuanto a la aplicación de sanciones".

\section{b) Modulación de los efectos: mantenimiento de los efectos sin nulidad}

El apartado 2 del art. 38 apodera al TACRECO u órgano análogo de las Comunidades Autónomas para modular los efectos de la declaración de nulidad, si considera que existen razones de interés público o general ("razones imperiosas de interés general" dice el precepto, siguiendo aquí la terminología que el texto de la ley hace de Directiva 207/66/CE, pese a las recomendaciones de cambio por el Consejo de Estado.

“1. Las consecuencias jurídicas de la declaración de nulidad por las causas previstas en el artículo anterior serán las establecidas en el artículo 35.1 de esta Ley. 2. No obstante lo dispuesto en el apartado anterior, el órgano competente para declarar la nulidad podrá acordar el mantenimiento de los efectos del contrato si, atendiendo las circunstancias excepcionales que concurran, considera que existen razones imperiosas de interés general que lo exijan...".

La primera cuestión que plantea el precepto comentado (y que también es trasladable a la modificación del artículo 110 de la Ley 31/2007) es la relativa al alcance de su apartado 2 pues, con arreglo a la redacción proyectada, se da a entender que el contrato es nulo pero que se excluye la sanción que lleva aparejada tal nulidad (la 94 privación de efectos). Lo que se excepciona es, aun concurriendo los presupuestos 
materiales definidos en el artículo precedente, la propia declaración en sí. Así resulta, por lo demás, de los términos de la Directiva 2007/66/CE (pues el artículo 2 sexies de la Directiva 89/665/CEE permite al órgano de recurso decidir si el contrato ha de considerarse ineficaz o si han de aplicarse sanciones alternativas) y de la propia redacción proyectada, que establece expresamente que la declaración de nulidad "deberá sustituirse" por una sanción alternativa".

Por razones imperiosas de interés general no deben entenderse únicamente las económicas, salvo que como señala expresamente el inciso segundo de apartado 2 del art. 39, salvo en los casos excepcionales en que la declaración de nulidad del contrato dé lugar a consecuencias desproporcionadas.

La ley da aquí, por tanto, un amplio margen al TACRECO u órgano autonómico que exigirá de prudencia y ponderación de los mismos de lo que puede ser consecuencias desproporcionadas entre fines y medios, de conformidad con la jurisprudencia comunitaria y ordinaria al uso.

La ley sigue diciendo en su tarea de delimitación de la noción de "razones imperiosas de interés generap" que "asimismo, no se considerará que constituyen razones imperiosas de interés general, los intereses económicos directamente vinculados al contrato en cuestión, tales como (i) los costes derivados del retraso en la ejecución del contrato, (ii) de la convocatoria de un nuevo procedimiento de contratación, (iii) del cambio del operador económico que habrá de ejecutar el contrato o de las obligaciones jurídicas derivadas de la nulidad.

Finalmente la ley señala que la resolución por la que se acuerde el mantenimiento de los efectos del contrato deberá ser objeto de publicación en el perfil de contratante previsto en el artículo 42 de esta Ley (nuevo articulo 53 TRCSP) ${ }^{26}$.

\section{c) La sustitución de la declaración de nulidad por las sanciones alternativas ex art. 38.3 de la Ley 30/2007}

El apartado 3 del art. 38 declarara expresamente que en el supuesto de no declarar la nulidad, tal declaración deberá sustituirse deberá sustituirse por alguna de las sanciones alternativas siguientes:

26 El art 42.2 del Texto Refundido de la Ley de Contratos de la Ley del Sector Público (RDLegislativo 3/2011, de 14 de noviembre), señala:

“ 2. El perfil de contratante podrá incluir cualesquiera datos e informaciones referentes a la actividad contractual del órgano de contratación, tales como los anuncios de información previa contemplados en el artículo 1415, las licitaciones abiertas o en curso y la documentación relativa a las mismas, las contrataciones programadas, los contratos adjudicados, los procedimientos anulados, y cualquier otra información útil de tipo general, como puntos de contacto y medios de comunicación que pueden utilizarse para relacionarse con el órgano de contratación. En todo caso deberá publicarse en el perfil de contratante la adjudicación de los contratos." 
a) La imposición de multas al poder adjudicador por un importe que no podrá ser inferior al $5 \%$ ni superar el $20 \%$ del precio de adjudicación del contrato. Cuando se trate de poderes adjudicadores cuya contratación se efectúe a través de diferentes órganos de contratación, la sanción alternativa recaerá sobre el presupuesto del departamento, consejería u órgano correspondiente que hubiera adjudicado el contrato.

Para determinar la cuantía en la imposición de las multas, la ley señala que el órgano competente tomará en consideración (i) la reiteración, (ii) el porcentaje del contrato que haya sido ejecutado o (iii) el daño causado a los intereses públicos o, en su caso, al licitador, de tal forma que éstas sean eficaces, proporcionadas y disuasorias.

b) La reducción proporcionada de la duración del contrato. En este caso, el órgano competente tomará en consideración la reiteración, el porcentaje del contrato que haya sido ejecutado o el daño causado a los intereses públicos o, en su caso, al licitador. Asimismo determinará la indemnización que corresponda al contratista por el lucro cesante derivado de la reducción temporal del contrato, siempre que la infracción que motive la sanción alternativa no le sea imputable.

(En sentido análogo se pronuncia el art. 110.3 de la ley 31/2007,) para la imposición de sanciones alternativas

Finalmente tanto el apartado 4 del mencionado art. 38 de la Ley 30/2007 como el art 110.4 de la ley 31/2007 especifica que lo dispuesto en todos los apartados anteriores se entenderá sin perjuicio de las sanciones de carácter disciplinario que corresponda imponer al responsable de las infracciones legales.

\section{d) Las advertencias del Consejo de Estado sobre la declaración de nulidad o su sustitución por sanciones alternativas}

El Consejo de Estado en su Dictamen de 28 de abril de 2010, al informar el Anteproyecto de ley advirtió sobre algunas de las consecuencias jurídicas de la declaración de nulidad, en los términos que siguen:

“1. Las consecuencias jurídicas de la declaración de nulidad por las causas previstas en el artículo anterior serán las establecidas en el artículo 35.1 de esta Ley. 2. No obstante lo dispuesto en el apartado anterior, el órgano competente para declarar la nulidad podrá acordar el mantenimiento de los efectos del contrato si, atendiendo las circunstancias excepcionales que concurran, considera que existen razones imperiosas de interés general que lo exijan...".

La primera cuestión que plantea el precepto comentado (y que también es trasladable a la modificación del artículo 110 de la Ley 31/2007) es la relativa al alcance de su apartado 2 pues, con arreglo a la redacción proyectada, se da a entender que el 96 contrato es nulo pero que se excluye la sanción que lleva aparejada tal nulidad (la 
privación de efectos). Lo que se excepciona es, aun concurriendo los presupuestos materiales definidos en el artículo precedente, la propia declaración en sí. Así resulta, por lo demás, de los términos de la Directiva 2007/66/CE (pues el artículo 2 sexies de la Directiva 89/665/CEE permite al órgano de recurso decidir si el contrato ha de considerarse ineficaz o si han de aplicarse sanciones alternativas) y de la propia redacción proyectada, que establece expresamente que la declaración de nulidad "deberá sustituirse" por una sanción alternativa.

Sería conveniente, pues, ajustar la redacción proyectada a las anteriores consideraciones. Lo más adecuado sería llevar la regulación contenida en los apartados 2 y 3 a un artículo independiente (observación que se realiza, fundamentalmente, de cara a la futura elaboración de un nuevo texto legal). Pero, no siendo esto posible en el marco de las vigentes Leyes 30/2007 y 31/2007, el título del precepto debería reflejar mejor esta posibilidad de sustituir la declaración de nulidad por una sanción alternativa (no se trata, por tanto, de una consecuencia jurídica de la declaración de nulidad). Y, por la misma razón, el párrafo introductorio del apartado 2 debería reformularse para recoger con mayor precisión la posibilidad de que el órgano de recurso no declare la nulidad de un contrato, pese a que concurran los presupuestos establecidos en el artículo precedente para ello, si razones imperiosas de interés general exigen que se mantengan sus efectos.

En cuanto a la terminología empleada, si es que se opta por mantener la expresión utilizada en la Directiva, debe revisarse el penúltimo párrafo del apartado 2, que alude a "circunstancias imperiosas" cuando debiera hacerlo a "razones imperiosas de interés general".

El tema de las sanciones alternativas previsto en la Directiva 2007/66/CE es uno de los más novedosos, al menos con arreglo al sistema español de contratación pública.

La regulación proyectada no suscita observación alguna desde el punto de vista de su adecuación a la Directiva 2007/66/CE pero es probable que plantee no pocos interrogantes a la hora de su puesta en práctica. Por ejemplo, un problema que se ha puesto de manifiesto en el expediente es que el precepto comentado no contiene previsión alguna sobre el destino que debe darse a la cantidad recaudada en concepto de sanción, si la sanción impuesta fuera una multa. Lo cual resultará especialmente relevante cuando el órgano de recurso no pertenezca a la Administración en la que se encuentra integrado el órgano de contratación.

Finalmente, la redacción proyectada de ambos preceptos ganaría en claridad si el contenido de su respectivo apartado 2 se desglosara en tres apartados: el primero, relativo a la posibilidad de sustituir la declaración de nulidad por una sanción alternativa, consistente en multa o en reducción de la duración del contrato, y en el que también podría incluirse los párrafos que aclaran el alcance de la expresión "razones imperiosas de interés general"; el segundo relativo a las multas; y el tercero relativo a la reducción proporcionada de la duración de los contratos. 
